Article

\title{
Synthesis and characterization of hierarchical nanoporous HY zeolites from acid-activated kaolin
}

\author{
Peter Adeniyi Alaba a , Yahaya Muhammad Sani a,b, Wan Mohd Ashri Wan Daud a,* \\ a Department of Chemical Engineering, University of Malaya, 50603 Kuala Lumpur, Malaysia \\ b Department of Chemical Engineering, Ahmadu Bello University, 870001 Nigeria
}

\section{A R T I C L E I N F O}

Article history:

Received 1 May 2015

Accepted 15 August 2015

Published 20 November 2015

\section{Keywords:}

HY zeolite

Kaolin

Hierarchical mesopore

Hierarchical factor

Relative crystallinity

\begin{abstract}
A B S T R A C T
Hierarchical nanoporous HY zeolites were synthesized from acid-activated kaolin. The hierarchical factor (HF) was maximized by varying the aging and crystallization time. This was achieved by maximizing the external surface area without greatly reducing the micropore volume. The resulting products were characterized using X-ray diffraction (XRD), X-ray fluorescence, $\mathrm{N}_{2}$ adsorption, and $\mathrm{NH}_{3}$ temperature-programmed desorption. The nanoporous HY zeolite with the highest HF was obtained by aging for $48 \mathrm{~h}$ and a crystallization time of $24 \mathrm{~h}$. The acidity and crystallinity varied depending on the operating parameters. Incorporation of an appropriate amount of $\mathrm{NaCl}$ was also vital in maximizing the HF, crystallinity, and acidity. The sample crystallinities were determined by comparing their XRD peak intensities with those of a conventional Y zeolite. The results show that optimizing this process could lead to a widely acceptable commercial route for HY zeolite production.
\end{abstract}

(C) 2015, Dalian Institute of Chemical Physics, Chinese Academy of Sciences. Published by Elsevier B.V. All rights reserved.

\section{Introduction}

Faujasitic zeolites have gained immense popularity within the research community and commercially. This is because they have a uniform pore size, high specific surface area (SSA), and thermal stability [1]. They also have tunable pores and acidities, and are therefore useful in various petrochemical processes [2]. However, their average pore size is low, which limits their use in processes that involve bulky molecules. Such processes include organic waste treatment, and heavy crude oil and bio-oil upgrading. This is because of their mass transfer hurdle in bulky chemical reactions [3]. Several researchers have reported strategies for overcoming this transport limitation for bulky molecules. These include dealumination, desilication, synthesis of mesoporous zeolites and microporous zeolites, and use of structure-directing agents [4]. The use of commercially available dual-pore materials obtained from crystal- line composite materials and crystalline physical mixtures has also been investigated $[5,6]$.

However, these strategies do not give satisfactory results in terms of acidity, and structural, thermal, and hydrothermal stability [7]. Recently, one of the most potent strategies has been the synthesis of nanocrystalline materials with more than one porosity level, termed hierarchical nanoporous materials. These materials synergistically combine the properties of mesoporous and microporous zeolites $[8,9]$. Hierarchical nanoporous materials have high thermal and hydrothermal stability and pore channels with a bimodal pore system (microand mesopores) [7,10]. The connection of microporous and mesoporous channels in a highly ordered manner enables the microporous channels to reside in the matrix. This results in shorter diffusion paths for reactant molecules [11].

Several researchers have worked on the synthesis of these bimodal materials [7,12,13]. Tan et al. [7] investigated the syn-

* Corresponding author. Tel: +60 3796 76897, +60 3796 75297; Fax: +60 3796 75319; E-mail: ashri@um.edu.my 
thesis of MY/kaolin composites with hierarchical mesoporous structure by overgrowth of mesoporous Y zeolites on kaolin. The synthesized MY/kaolin composites have short diffusion paths, high hydrothermal stability, and moderate acidities. However, they have low hierarchical factors (HFs), and the starting materials for the synthesis are expensive. It is therefore imperative to investigate the possibility of synthesizing hierarchical nanoporous zeolites from cheaper starting materials.

Kaolin clay mineral catalysts have been used in industrial application since the early 1930s. Significant progress in several industries such as the petrochemical industry, especially catalytic refining and bulk chemistry, became possible by using kaolinite as a precursor in active catalyst synthesis. This is because of the kaolin structure and pore size, which are suitable for the conversion of bulky molecules [14]. These factors explain the renewed interest in clay aluminosilicates for zeolite synthesis. However, kaolinites resist acid attack during activation because of their high octahedral alumina contents. Calcination at temperatures between 550 and $950{ }^{\circ} \mathrm{C}$ decreases this resistance by transforming the clay into metakaolin. However, this transformation deforms the crystalline structure of the clay. Liu et al. [15] investigated synthesis of $\mathrm{NaY}$ zeolites from coal-based kaolin. They reported that the optimum crystallization temperature is $107^{\circ} \mathrm{C}$; this gives a higher SSA and crystallinity.

In this work, we investigated the hydrothermal synthesis of hierarchical nanoporous HY zeolites from acid-activated metakaolin. The effects of aging, crystallization time, and $\mathrm{NaCl}$ incorporation on the crystallinity and HF of the synthesized HY zeolites were systematically investigated.

\section{Experimental}

\subsection{Materials and catalyst preparation}

Kaolin, $\mathrm{NaOH}$, and $\mathrm{H}_{2} \mathrm{SO}_{4}$ (95\%-98\% pure) were obtained from R\&M Chemicals Sdn. Bhd., Malaysia. The reagents were used without further purification.

The HY zeolite precursor was obtained by thermal activation at $850{ }^{\circ} \mathrm{C}$ for $2 \mathrm{~h}$, followed by activation with $\mathrm{H}_{2} \mathrm{SO}_{4}$ (4 $\mathrm{mol} / \mathrm{L}$ ) at $90{ }^{\circ} \mathrm{C}$ for $3 \mathrm{~h}$ to produce amorphous aluminosilicate. After drying and calcination at $550^{\circ} \mathrm{C}$ for $2 \mathrm{~h}$, the precursor was added to an aqueous $\mathrm{NaOH}$ solution (14\%) at a solute/solution ratio of 1:9. The solution was aged at room temperature for 24 to $72 \mathrm{~h}$ and then crystallized at $100{ }^{\circ} \mathrm{C}$ for $16-24 \mathrm{~h}$. The resulting mixture was washed with distilled water and filtered, using a vacuum pump, until the $\mathrm{pH}$ was 9-10. The sample was dried at $110{ }^{\circ} \mathrm{C}$ overnight and then soaked with saturated $\mathrm{NaCl}$ solution to its equilibrium water content $[16,17]$. The sample was placed in a fume cupboard for removal of excess water and dried. The sample was transformed into the hydronium form in ammonium nitrate solution ( $0.2 \mathrm{~mol} / \mathrm{L})$ for $24 \mathrm{~h}$. The resulting solution was filtered; the residue was dried at $110^{\circ} \mathrm{C}$ overnight and then calcined at $550{ }^{\circ} \mathrm{C}$ for $2 \mathrm{~h}$. The obtained samples are denoted by HY- $x-y$, where $x$ represents the aging period (d), and $y$ represents the crystallization time (h); for example, the sample aged for $1 \mathrm{~d}$ and crystalized for $16 \mathrm{~h}$ is denoted by HY-1-16, and the sample without $\mathrm{NaCl}$ is denoted by HY-1-16_ns.

\subsection{Characterization}

The silica and alumina contents of the synthesized HY zeolites were determined using X-ray fluorescence. X-ray diffraction (XRD; Philip X'pert X-ray diffractometer) was performed using nickel-filtered $\mathrm{Cu} K_{\alpha}$ radiation $(\lambda=0.1544 \mathrm{~nm})$ in the $2 \theta$ range from $5.018^{\circ}$ to $69.966^{\circ}$, with a step size of $0.026^{\circ}$. The (511), (440), (533), and (642) reflections were used to determine the average crystal size and relative crystallinities of the samples [18]. The crystallite sizes were calculated using PANalytical X'Pert HighScore Plus v.4.0 software [19]. We compared the crystallinities of the samples with that of a conventional $\mathrm{Y}$ zeolite to obtain the relative crystallinities (RC):

RC (\%) $=\frac{\text { Sum of sample characteristic peak intensities }}{\text { Sum of reference characteristic peak intensities }} \times 100$

$\mathrm{N}_{2}$ adsorption/desorption analysis was performed using a surface area and porosity analyzer (Micromeritics ASAP 2020) at $-196^{\circ} \mathrm{C}$.

We used a Chemisorp 2720 instrument to perform $\mathrm{NH}_{3}$ temperature-programmed desorption ( $\mathrm{NH}_{3}$-TPD) analysis. The instrument consisted of a TPx quartz sample tube microreactor installed in a vertical furnace. The desorption signal was detected using an online thermal conductivity detector (TCD). The sample (about $0.2 \mathrm{~g}$ ) was placed in the microreactor and supported with quartz wool. Sample purging was performed using He flow (20 mL/min) at $550{ }^{\circ} \mathrm{C}$ for $2 \mathrm{~h}$. The physisorbed $\mathrm{NH}_{3}$ was then flushed out with the flow $(20 \mathrm{~mL} / \mathrm{min})$ at $110{ }^{\circ} \mathrm{C}$ for $1 \mathrm{~h}$. $\mathrm{NH}_{3}$-TPD was performed from 70 to $500{ }^{\circ} \mathrm{C}$ in $\mathrm{He}$ flow $(20 \mathrm{~mL} / \mathrm{min})$ at $10{ }^{\circ} \mathrm{C} / \mathrm{min}$, with continuous monitoring of desorbed $\mathrm{NH}_{3}$ by the TCD.

\subsection{Hierarchical factor}

The HF is used to categorize the degree of structural order of a porous material; it estimates the degree to which the formation of fewer mesopores decreases micropore formation in a synthesized zeolite sample [20-23].

Zheng et al. [20] proposed a model for classification of hierarchical mesoporous zeolites based on conventional $\mathrm{N}_{2}$ adsorption/desorption analysis. They defined HF using the ratio of the micropore volume to the mesopore volume $\left(V_{\text {micro }} / V_{\text {meso }}\right)$ and relative mesopore SSA $\left(S_{\text {meso }} / S_{\mathrm{BET}} ; S_{\mathrm{BET}}\right.$ is the Brunauer-Emmett-Teller surface area) of the weighed sample:

$$
\mathrm{HF}=\frac{V_{\text {micro }} \times S_{\text {meso }}}{V_{\text {meso }} \times S_{\text {BET }}}
$$

\section{Results and discussion}

\subsection{Characterization}

Table 1 shows the silica and alumina compositions and Si/Al molar ratios of the HY zeolites produced from acid-activated metakaolin, and Fig. 1 shows the XRD patterns of the synthe- 
Table 1

Silica and alumina contents of the samples.

\begin{tabular}{lccc}
\hline Sample & $\mathrm{Si}(\mathrm{wt} \%)$ & $\mathrm{Al}(\mathrm{wt} \%)$ & $n(\mathrm{Si}) / n(\mathrm{Al})$ \\
\hline HY-1-16 & 44.49 & 25.17 & 1.57 \\
HY-1-16_ns & 43.74 & 27.60 & 1.39 \\
HY-2-16 & 45.46 & 25.84 & 1.55 \\
HY-2-24 & 47.00 & 25.70 & 1.61 \\
HY-3-16 & 42.69 & 26.99 & 1.39 \\
\hline
\end{tabular}

sized catalysts with standard XRD peak positions. The results show a slight decrease in the $\mathrm{Si} / \mathrm{Al}$ molar ratio as the aging time increases from 24 to $48 \mathrm{~h}$, but a rapid decrease in increasing aging to $72 \mathrm{~h}$. As the crystallization time increases from 16 to $24 \mathrm{~h}$, the Si/Al molar ratio increases from 1.55 to 1.61. The XRD patterns of the samples show purely $\mathrm{Y}$ zeolite characteristic peaks (from (511), (440), (533), and (642)) without the presence of $4 \mathrm{~A}, \mathrm{P}$, and MOR zeolite peaks. The results show that all the samples have the characteristic peaks of Y zeolites, but with lower intensity. The sample HY-3-16 has the lowest-intensity peaks.

The intensities of the characteristic peaks from the (511), (440), and (533) reflections are lower than those of the other peaks, and are nearly invisible in Fig. 1; more detail is shown in Fig. 2. This is because excess aging impedes crystallization. Table 2 lists the relative crystallinities and average crystal sizes of the catalysts, calculated using PANalytical X'Pert HighScore software from the reflection peaks (511), (440), (533), and (642). The optimum aging time is $2 \mathrm{~d}$, and the optimum crystallization time is $16 \mathrm{~h}$. This shows that excess aging and crystallization are detrimental to the HY zeolite crystallinity. The crystallinity of the sample without $\mathrm{NaCl}$ incorporation is lower than that of the sample with incorporated $\mathrm{NaCl}$. The average crystal sizes of all the samples confirm that they are nanoporous.

These results confirm that the synthesized HY zeolites have hierarchical nanoporosity.

Table 3 shows the results of the surface area and porosity analysis, performed using $\mathrm{N}_{2}$ adsorption/desorption isotherms at a relative pressure $\left(p / p_{0}\right)$ of 0.98 . The BET model was used to obtain the SSAs and pore size distributions from the isotherms. The table also includes the computed HF values. Fig. 3 shows the $\mathrm{N}_{2}$ adsorption/desorption isotherms of the HY zeolite samples. At $p / p_{0}=0.7$, the samples show substantial increases in adsorption, and the desorption curves show hysteresis loops.

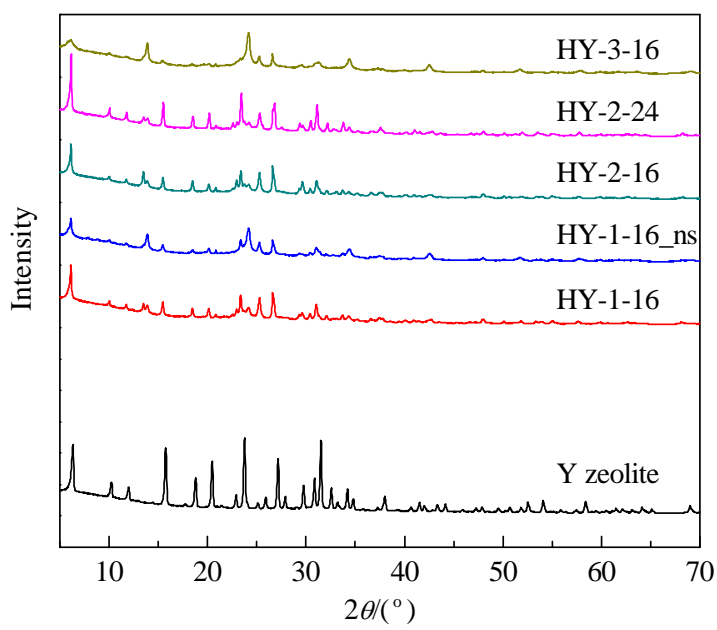

Fig. 1. XRD patterns of synthesized HY zeolites.

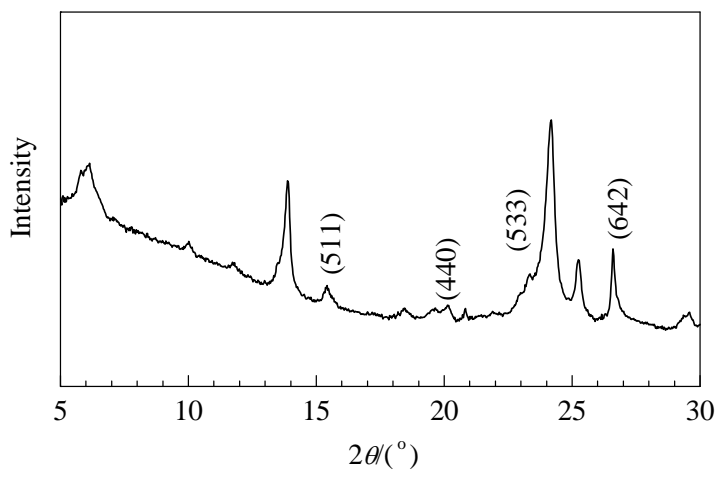

Fig. 2. XRD pattern of synthesized HY-3-16 zeolite.

Table 2

Relative crystallinities and average crystal size of synthesized nanoporous HY zeolites, calculated from XRD data.

\begin{tabular}{lccc}
\hline Sample & $\begin{array}{c}\text { Total relative } \\
\text { intensity }\end{array}$ & $\begin{array}{c}\text { Relative } \\
\text { crystallinity }\end{array}$ & $\begin{array}{c}\text { Average crystal } \\
\text { size (nm) }\end{array}$ \\
\hline Y zeolite & 288.90 & - & - \\
HY-1-16 & 181.24 & 62.73 & 74.72 \\
HY-1-16_ns & 143.75 & 49.76 & 70.29 \\
HY-2-16 & 199.66 & 69.11 & 90.60 \\
HY-2-24 & 147.08 & 50.91 & 82.58 \\
HY-3-16 & 76.29 & 26.41 & 68.57 \\
\hline
\end{tabular}

a Computed using the relative intensity of the samples relative to the relative intensity of conventional $\mathrm{Y}$ zeolite.

${ }^{\mathrm{b}}$ Computed using the peak area of the samples relative to the peak area of conventional Y zeolite.

Table 3

Textural parameters of synthesized HY zeolites.

\begin{tabular}{lcccccccc}
\hline Sample & $\begin{array}{c}S_{\text {BET }} \\
\left(\mathrm{m}^{2} / \mathrm{g}\right)\end{array}$ & $\begin{array}{c}S_{\text {micro }} \text { a } \\
\left(\mathrm{m}^{2} / \mathrm{g}\right)\end{array}$ & $\begin{array}{c}S_{\text {meso }} \text { a } \\
\left(\mathrm{m}^{2} / \mathrm{g}\right)\end{array}$ & $\begin{array}{c}V_{\text {total }} / \\
\left(\mathrm{cm}^{3} / \mathrm{g}\right)\end{array}$ & $\begin{array}{c}V_{\text {micro }} \text { a } \\
\left(\mathrm{cm}^{3} / \mathrm{g}\right)\end{array}$ & $\begin{array}{c}D_{\text {meso }} \text { b/ } \\
\mathrm{nm}\end{array}$ & $\begin{array}{c}\text { Acid site } \\
(\mathrm{mmol} / \mathrm{g})\end{array}$ \\
\hline HY-1-16 & 248.73 & 222.54 & 26.19 & 0.18 & 0.10 & 4.87 & 0.147 \\
HY-1-16_ns & 181.67 & 147.86 & 38.80 & 0.19 & 0.07 & 4.12 & 0.108 \\
HY-2-16 & 199.98 & 175.28 & 24.69 & 0.15 & 0.08 & 3.05 & 0.142 \\
HY-2-24 & 316.50 & 287.62 & 28.88 & 0.19 & 0.13 & 2.42 & 0.214 \\
HY-3-16 & 167.98 & 126.63 & 41.36 & 0.20 & 0.06 & 4.87 & 0.26 \\
\hline
\end{tabular}

${ }^{a}$ Calculated from the $t$-plot curve.

bBET method. 


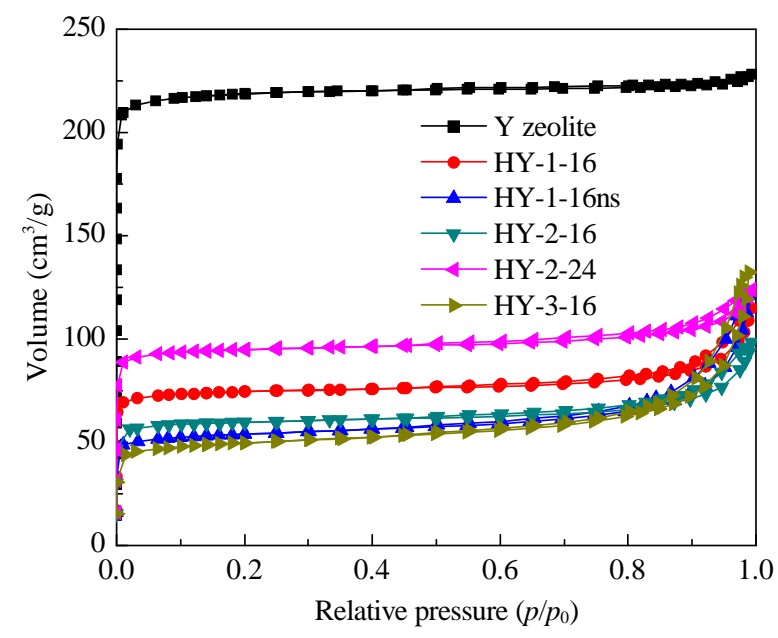

Fig. 3. $\mathrm{N}_{2}$ adsorption/desorption isotherms of HY zeolite samples.

Fig. 4 shows the $\mathrm{NH}_{3}$-TPD curves for the synthesized HY zeolite samples. These were used to determine the numbers and strengths of the acidic sites. The samples show a well-resolved symmetric peak at about $180{ }^{\circ} \mathrm{C}$ and a shoulder at about $300{ }^{\circ} \mathrm{C}$. This shows that the HY zeolite samples have high numbers of mildly acidic sites. These sites can suppress catalyst deactivation in catalytic cracking, as reported by Konno et al. [24,25]. Mesoporosity can improve the properties of zeolites by preventing secondary reactions by decreasing the diffusion path length; this aids selectivity. Table 3 shows the total numbers of acidic sites, determined from the TPD peak areas of the samples. The results show that as aging increases from 1 to $3 \mathrm{~d}$, the number of acidic sites decreases from 1.43 to $0.83 \mathrm{mmol} / \mathrm{g}$ after crystallization for $16 \mathrm{~h}$. However, an increase in the crystallization time from 16 to $24 \mathrm{~h}$ increases the number of acidic sites from 1.26 to $2.06 \mathrm{mmol} / \mathrm{g}$. Incorporation of $\mathrm{NaCl}$ also improves the acidity.

\subsection{Effect of aging period, crystallization time, and $\mathrm{NaCl}$ incorporation on formation of HY zeolites}

The effect of aging is important in zeolite synthesis. Tables 2 and 3 show the effects of aging on the crystallinity, SSA, HF, and

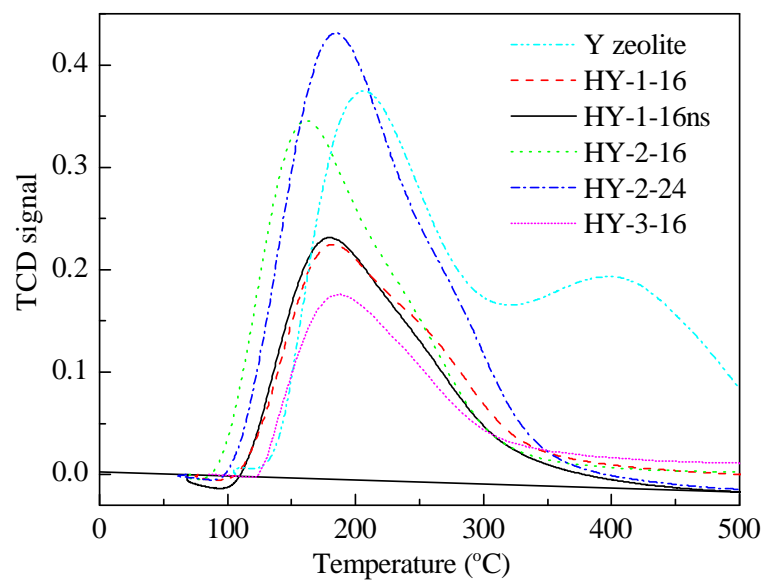

Fig. 4. $\mathrm{NH}_{3}$-TPD curves for synthesized nanoporous $\mathrm{HY}$ zeolites.

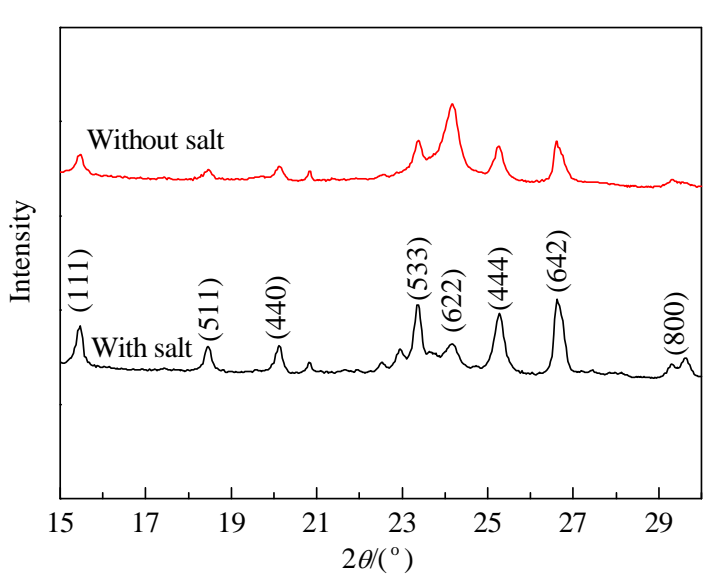

Fig. 5. XRD patterns for samples with and without $\mathrm{NaCl}$, aged for $1 \mathrm{~d}$ and crystallized for $16 \mathrm{~h}$.

acidity. The most appropriate aging time is $1 \mathrm{~d}$, because this gives the highest SSA for all samples hydrothermally crystallized for $16 \mathrm{~h}$. Further increases in the aging period are detrimental to HY zeolite synthesis, because they lead to reductions in the HF, SSA, crystallinity, micropore volume, and number of acidic sites in the samples.

The effect of crystallization is also important in HY zeolite synthesis. Table 2 shows that crystallization for $16 \mathrm{~h}$ gives the highest relative crystallinity. An increase in the crystallization time from 16 to $24 \mathrm{~h}$ for the sample aged for $2 \mathrm{~d}$ greatly reduces the pore size and crystal size, but increases the number of acidic sites, SSA, total pore volume, micropore volume, and HF, as shown in Table 3.

The purpose of $\mathrm{NaCl}$ incorporation is to enhance the crystallinity and hydrothermal stability and maintain the initial porous structure. However, excess $\mathrm{NaCl}$ causes the mesopore walls of mesoporous materials to collapse [16,17]. Fig. 5 shows the XRD patterns for nanoporous HY zeolites with and without $\mathrm{NaCl}$ incorporation. The XRD reflection peaks from (511), (440), (533), and (642) for the samples with $\mathrm{NaCl}$ are more highly resolved than those for the sample without $\mathrm{NaCl}$. The non-faujasitic peak from (622), which is more pronounced in the XRD pattern of the non-salted sample, may account for its lower crystallinity. This indicates that the $\mathrm{NaCl}$ incorporation method proposed by Chandrasekhar and Pramada [16], which was used in this work, is appropriate. $\mathrm{NaCl}$ incorporation not only enhances the relative crystallinity, SSA, pore size, and HF, but also increases the number of acidic sites in the sample.

\section{Conclusions}

Hierarchical nanoporous HY zeolites with maximum HF values were synthesized. This was accomplished by varying the aging and crystallization time. Crystallite sizes of about 68-91 $\mathrm{nm}$ and $\mathrm{Si} / \mathrm{Al}$ ratios ranging from 1.39 to 1.61 were obtained. The aging time was varied from 1 to $3 \mathrm{~d}$; the optimum aging period was $1 \mathrm{~d}$. The sample aged for $2 \mathrm{~d}$ was crystallized for 16 or 24 h. Sample HY-2-24 had the lowest relative crystallinity but highest number of acidic sites, Si/Al ratio, surface area, and HF. NaCl incorporation after crystallization also enhanced the 


\title{
Graphical Abstract
}

Chin. J. Catal., 2015, 36: 1846-1851 doi: 10.1016/S1872-2067(15)60962-7

Synthesis and characterization of hierarchical nanoporous HY zeolites from acid-activated kaolin

Peter Adeniyi Alaba, Yahaya Muhammad Sani, Wan Mohd Ashri Wan Daud* University of Malaya, Malaysia; Ahmadu Bello University, Nigeria

We investigated the effects of aging and crystallization time, and $\mathrm{NaCl}$ incorporation on the formation of hierarchical nanoporous HY zeolites. These three factors influenced the acidity, crystallinity, hierarchical factor, and surface area.

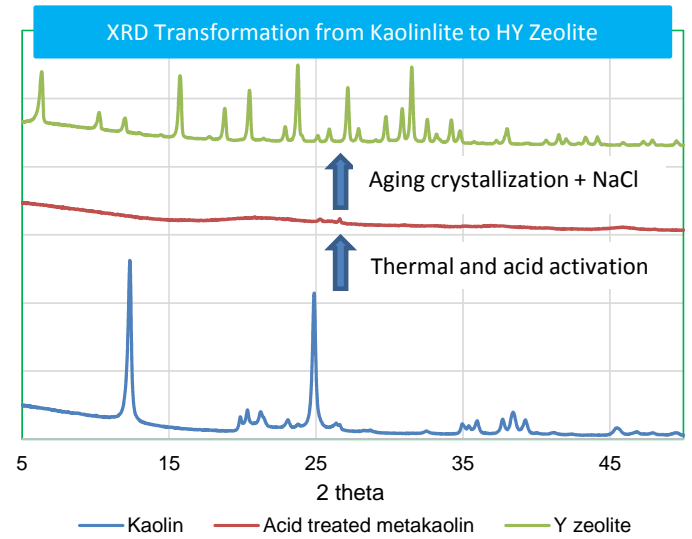

- Kaolin — Acid treated metakaolin —Y zeolite
$\mathrm{HF}$, number of acidic sites, and relative crystallinity, and preserved the mesoporous structure. A highly crystalline, mildly acidic, hierarchical nanoporous HY zeolite with a high surface area was therefore obtained by varying the aging and crystallization time.

\section{Acknowledgments}

This work was fully funded by Fundamental Research Grant Scheme, University of Malaya through the project number of FP031-2013A. We also like to acknowledge the valuable help from the instrument laboratory of Chemical Engineering Department in regard to provide the facility for acidity analysis which supported by PG144-2012B.

\section{References}

[1] Karami D, Rohani S. Chem Eng Process, 2009, 48: 1288

[2] Shen S C, Chen Q, Chow P S, Tan G H, Zeng X T, Wang Z, Tan R B H.J Phys Chem C, 2007, 111: 700

[3] Verhoef M J, Kooyman P J, van der Waal J C, Rigutto M S, Peters J A, van Bekkum H. Chem Mater, 2001, 13: 683

[4] Groen J C, Moulijn J A, Pérez-Ramírez J. J Mater Chem, 2006, 16: 2121

[5] Guo W P, Huang L M, Deng P, Xue Z Y, Li Q Z. Microporous Mesoporous Mater, 2001, 44-45: 427

[6] Huang L M, Guo W P, Deng P, Xue Z Y, Li Q Z. J Phys Chem B, 2000, 104: 2817

[7] Tan Q F, Bao X J, Song T C, Fan Y, Shi G, Shen B, Liu C H, Gao X H. J Catal, 2007, 251: 69
[8] Ogura M, Shinomiya S Y, Tateno J, Nara Y, Nomura M, Kikuchi E, Matsukata M. Appl Catal A, 2001, 219: 33

[9] Jacobsen C J H, Madsen C, Houzvicka J, Schmidt I, Carlsson A. J Am Chem Soc, 2000, 122: 7116

[10] Han Y, Wu S, Sun Y Y, Li D S, Xiao F S, Liu J, Zhang X Z. Chem Mater, 2002, 14: 1144

[11] van Donk S, Janssen A H, Bitter J H, de Jong K P. Catal Rev-Sci Eng, 2003, 45: 297

[12] Xu M C, Cheng M J, Bao X H. Chem Commun, 2000: 1873

[13] Rong T J, Xiao J K. Mater Lett, 2002, 57: 297

[14] Lenarda M, Storaro L, Talon A, Moretti E, Riello P. J Colloid Interface Sci, 2007, 311: 537

[15] Liu X M, Yan Z F, Wang H P, Luo Y T. J Nat Gas Chem, 2003, 12: 63

[16] Chandrasekhar S, Pramada P. Appl Clay Sci, 2004, 27: 187

[17] Yu J, Shi J L, Chen H R, Yan J N, Yan D S. Microporous Mesoporous Mater, 2001, 46: 153

[18] Hosseinpour N, Mortazavi Y, Bazyari A, Khodadadi A A. Fuel Process Technol, 2009, 90: 171

[19] Frunz L, Prins R, Pirngruber G D. Microporous Mesoporous Mater, 2006, 88: 152

[20] Zheng J J, Yi Y M, Wang W L, Guo K, Ma J H, Li R F. Microporous Mesoporous Mater, 2013, 171: 44

[21] Pérez-Ramírez J, Verboekend D, Bonilla A, Abello S. Adv Funct Mater, 2009, 19: 3972

[22] Zheng J J, Zeng Q H, Yi Y M, Wang Y, Ma J H, Qin B, Zhang X W, Sun W F, Li R F. Catal Today, 2011, 168: 124

[23] Zheng J J, Zeng Q H, Zhang Y Y, Wang Y, Ma J H, Zhang X W, Sun W F, Li R F. Chem Mater, 2010, 22: 6065

[24] Konno H, Tago T, Nakasaka Y, Ohnaka R, Nishimura J I, Masuda T. Microporous Mesoporous Mater, 2013, 175: 25

[25] Konno H, Okamura T, Kawahara T, Nakasaka Y, Tago T, Masuda T. Chem Eng J, 2012, 207-208: 490

\section{由酸活化高岭土制备多级纳米孔HY分子篮及其表征}

\author{
Peter Adeniyi Alaba a , Yahaya Muhammad Sani ${ }^{\text {a,b }}$, Wan Mohd Ashri Wan Daud ${ }^{\text {a,* }}$ \\ 马来西亚大学化学工程系, 吉隆坡50603, 马来西亚 \\ ${ }^{\mathrm{b}}$ 艾哈迈杜·贝罗大学化学工程系, 870001, 尼日利亚
}

摘要: 由酸活化的高岭土制备了多级纳米孔HY分子篮. 通过改变老化时间和晶化时间可得到最大的多级因子(HF), 此时外比表 面积最大而微孔孔体积变化不大. 运用X射线衍射(XRD)、X射线荧光光谱、 $\mathrm{N}_{2}$ 吸附-脱附法和 $\mathrm{NH}_{3}$ 程序升温脱附对所得样品进行 
了表征. 老化 $2 \mathrm{~d}$ 和晶化 $24 \mathrm{~h}$ 所制的纳米孔HY分子篮样品的HF值最大. 样品的酸性和结晶度也随着制备条件而变化. 另外, 适量 $\mathrm{NaCl}$ 的嵌入对提高对所制样品的HF值、酸性和结晶度起到重要作用. 通过比较样品和常规HY分子篎的XRD峰强度算得样品的 结晶度. 结果表明, 优化合成条件可得到广泛适用于工业化的分子耖制备路线.

关键词: HY分子篮; 高岭土; 多级中孔; 多级因子; 相对结晶度

收稿日期: 2015-05-01. 接受日期: 2015-08-15. 出版日期: 2015-11-20.

*通讯联系人. 电话: +60 $379676897,+603796$ 75297; 传真: +60 3796 75319; 电子信箱: ashri@um.edu.my

本文的英文电子版由Elsevier出版社在ScienceDirect上出版(http://www.sciencedirect.com/science/journal/18722067). 